\title{
LA VOZ Y LA MIRADA DE LA MUJER MUSULMANA
}

\author{
Lic. D. ${ }^{a}$ Oñez Monjas Hernández \\ Universidad de Málaga. España
}

\author{
"ISLAM" \\ "PAZ, SUMISIÓN Y OBEDIENCIA A DIOS".
}

\section{INTRODUCCIÓN}

Es para mi un inmenso honor el poder participar en este ilustre Congreso en el que insignes y relevantes personalidades del mundo universitario y de la cultura nos deleitan con su buen hacer y sus últimos trabajos de investigación. Mi pequeña aportación pretende ser un sencillo acercamiento a la difícil y compleja situación de la mujer musulmana desde el mayor de los respetos por el Islam y desde la más profunda admiración por la cultura islámica, una de las más ricas y sorprendentes del planeta. Islamismo no significa integrismo aunque se den en muchas ocasiones la mano. Supone, sin duda alguna, un pequeño gran reto intentar analizar en unos pocos minutos toda la dimensión humana plural de millones de mujeres que viven en el mundo musulmán (Dar al Islam) tan diverso y heterogéneo según las diferentes y peculiares formas culturales musulmanas existentes.

El Islam, que como señala el profesor Martínez Montávez no es sólo un fenómeno histórico importantisimo; es también una realidad actual" constituye, así mismo, un amplio fenómeno pluricultural, multirracial e intercontinental que se extiende por los cinco continentes siendo en 58 paises, la población musulmana superior al $50 \%{ }^{2}$ (Según otras fuentes no islamicas el número de países de mayoría musulmana sería de 55). La realidad de la mujer musulmana está inscrita en unas circunstancias concretas y específicas según los distintos países, y presenta diferentes peculiaridades según los diversos regímenes politicos y los plurales entornos sociales y culturales. Nawal Al-Sa'dawi nos dice:

I MARTINEZ MONTÁVEZ, Pedro, El Islam, Salvat. Barcelona, 1991, p. 8.

2 WAMY (ASAMBLEA MUNDIAL DE LA JUVENTUD MUSULMANA), Comprender El'Islam, Dar-alWattan. Riad, 1992, p. 10. 
"Que escribir sobre la mujer en la sociedad árabe, especialmente si la que lo hace es una mujer, supone adentrarse en un terreno dificil y susceptible de herir muchas sensibilidades. Es como ir abriéndose camino a través de un campo sembrado de minas que, a veces, se ven, pero otras, están ocultas". ${ }^{3}$

Es complicado "desvelar" (la mirada) y analizar rasgos comunes y situaciones más o menos generalizadas (las circunstancias, las tradiciones y costumbres varian de un lugar a otro o de un país a otro, o existen diferencias según sea la etnia -árabe, beréber...-, por el hecho de vivir en el campo o en la ciudad, por la situación socioeconómica y cultural, según se practique o no los preceptos religiosos, etc.), arraigadas por la ortodoxia religiosa, y como se producen intentos de transformación y evolución (la voz) en un contexto cambiante y diversificado que obedece a numerosos factores y causas. Entre tantos factores a tener en cuenta en este breve análisis, se encuentra la controversia entre "lo occidental" y "lo tradicional" y todo ello insertado en la evolución misma de la Humanidad, en un mundo interrelacionado y cambiante, lleno de interconexiones, desigualdades, ósmosis, desequilibrios, intereses, discriminaciones, binomios (pobreza-riqueza...), intercambios, pluralidad...

Para acercarnos a la mujer musulmana es necesario aproximarse a la religión islámica ya que no sólo supone conocer la espiritualidad y las creencias de todo un pueblo, sino la normativa, los principios, las pautas de conducta que rijen la vida personal, familiar y social como código ético que es. El Islam mantiene una interconexión plena entre todos los ámbitos de la vida: moral, religioso, familiar y social y la ortodoxia se circunscribe básicamente a la creencia en Dios y en su Profeta y en la observancia de la Ley.

Acogiéndonos a su inmensa hospitalidad, emprenderemos un camino fraternal de conocimiento y amistad en el que ellas tendrán la palabra. Nos acercaremos a su vida y a la tragedia de su "mutilación" e incluso su muerte, a sus inquietudes y sus sufrimientos. Intentaremos ver a través de sus ojos y escucharemos, desde su "obligado susurro", valientes manifestaciones sobre una existencia a menudo basada en la "doble imagen" ( $L a$ voz y la mirada de la mujer musulmana). Deseo parecerme, como diría Bertolt Brecht, "al que llevaba el ladrillo consigo para mostrar al mundo cómo era su casa". Espero de corazón que el minúsculo "ladrillo" que supone el contenido de mis palabras no solamente muestre y descubra algo más sobre la realidad, a veces durísima y extrema de tantas mujeres musulmanas, sino que con él se contruyan puentes de diálogo, de comprensión y ayuda.

3 AL-SA'DAWI, Nawal, La cara desmuda de la mujer árabe, "horas y Horas la editorial". Madrid, 1991, p. 18. 
"Ya sabemos lo que es. Ya sabemos en qué reside nuestra tragedia. Hemos nacido de un sexo especial, el sexo femenino.

Estamos destinadas a padecer la miseria y a vivir con una parte del cuerpo mutilada por unas manos frias, insensibles y crueles". NAWAL AL-SA'DAWI

\section{EL DOLOROSO COMIENZO DE SER MUJER}

\subsection{Es una niña ("Bint")}

El nacimiento de una niña no se celebra con los signos festivos que acompañan el nacimiento de un varón. Los hombres cuando se enteran de que en una familia ha nacido un varón van corriendo al marido, le rasgan las vestiduras por completo en señal de regocijo y alegria extremas y con palabras como éstas exclaman: ¡Enhorabuena una niña no vale nada pero un hijo hace una nacion!

"Desde el dia en que abri los ojos a la vida, la sociedad me habia hecho sentir. que era una niña y me habia enseñado que casi siempre, después de la palabra "bint", alguien frunce el ceño". 4

Mujeres que desde la cuna comienzan a ser y a sentirse diferentes por el hecho de haber nacido niñas y no haber "tenido la suerte" de haber nacido niños. Desde la misma concepción se sueña, se desea, se espera a un hijo... tanto por parte de la madre, como por parte del padre, incluso de la familia. La llegada de una niña al mundo no resulta "tan importante", "tan valiosa"... Es muy duro tener que oir a un familiar próximo, a tu abuela, exclamar: “Ojalá hubieras sido niño"...Inmediatamente surge el por qué, la causa, el motivo, la razón de esta incognita: ¿Por qué?... Y la pregunta continua y sigue formulándose... y siguen formulándosela multitud de mujeres y la mayoría de ellas sin encontrar respuesta, sin encontrar una salida...

"Pero mi madre y mi padre siempre me contestaban igual: "Es asi...". A lo que yo replicaba: "Y ¿Por qué tiene que ser asi?”. Y siempre obtenia las mismas palabras como respuesta: "Porque es asi". Algunas veces me obstinaba y repetia la misma pregunta. Entonces, a punto de perder la paciencia, me decian casi al unisono: "Él es un niño, y tú, una niña".'

Y no aparecen con los años, con el tanscurrir del tiempo, razones convincentes, explicaciones de peso, argumentos sólidos...sólo "Porque es asi". Ese " $Y$ ¿Porque es asi?" le acompañará desde la cuna hasta la tumba... Las miradas que percibe a su alrededor es la de "haber nacido incompleta", de "faltarle algo" pese a que sea el bebé más sano del mundo... $Y$ de nuevo el “¿Por qué?”... En algunas familias, sobre todo de las zonas rurales, caen en una profunda tristeza, en la apatía, el desaliento, e incluso en depresiones. Puede llegar el

4 AL-SA'DAWI, N., La cara desnuda..., p. 27.

5 lbid., p. 29. 
caso de que se "castigue" a la madre, se la recrimine, insulte, agreda o incluso se llegue al divorcio. En un informe elaborado por el Instituto Panos de Londres se califica como "holocausto silenciado" la realidad de una discriminación que comienza desde el mismo nacimiento: infanticidio, falta de atención sanitaria, subalimentación deliberada, etc... son algunas de las causas. La mortalidad infantil es, en general, en la mayoría de los países árabes muy elevada, siendo superior la de las niñas a la de los niños, debido a que normalmente se las trata con menor cuidado y se cometen, por tanto, un mayor número de negligencias. Si la niña nace en una familia con un nivel cultural más elevado, en un área urbana, se la acogerá con mayor humanidad y con menos pesar pero rápidamente se la inculcará en el especial cuidado de sus órganos sexuales (comprenderá la importancia de su himen), se la rodeará de un ambiente cargado de miedos, de prohibiciones, de tabúes respecto al sexo y se la educará en la observancia de las reglas del Islam.

\subsection{La "mutilación"}

La escisión del clítoris de las niñas es una práctica común en muchos países del mundo. Según informes de las Naciones Unidas se estima que unos 135 millones de niñas y de mujeres han sufrido algún tipo de mutilación genital en 28 paises del mundo, calculándose que cada año alrededor de 2 millones de mujeres corren el riesgo de padecer esta terrible "operación" (6.000 niñas al día, cinco por minuto). Las tres cuartas partes de las afectadas pertenecen a cinco países: Nigeria, Etiopía, Egipto, Sudán y Kenya. En Somalia, por ejemplo, se considera que al $98 \%$ de las mujeres se les mutilan los genitales (día del "gudniin") y según Amnistía Internacional hay muchos otros países con un alto porcentaje estimado que sufren la escisión como Yibuti (entre 90\% y 98\%), Egipto con un 97\%, Malí (entre 90 y $94 \%$ ) y Eritrea y Etiopía con un $90 \%$ entre otros. Se han recogido también informes de mutilaciones genitales femeninas (M.G.F.) en países como Francia, Reino Unido, Italia, Países Bajos, Suecia, Dinamarca, EE.UU. o Australia.

Pese a que los origenes son inciertos se calcula que se lleva realizando desde hace 4.000 años por lo que comenzó a practicarse antes de la llegada del Islam y ya estaba muy extendida en algunas partes del mundo incluida la Península Arábiga remontándose a los reinos faraónicos del antiguo Egipto (en Sudán se denomina "escisión faraónica") y mencionada por Heródoto 700 años a. de C. Esta cruel operación se ha visto acompañada desgraciadamente de otras prácticas aún más salvajes. Desmond Morris afirma:

"Una de ellas consistia en enterrarlas vivas casi inmediatamente después de nacer $o$, incluso, un poco después. Otros ejemplos son el cinturón de castidad o de la apertura de los órganos genitales de alambre y un cerrojo especial de hierro"."

La razón principal para que se lleve a cabo y se siga practicando este ritual es la conservación de la virginidad con el correspondiente himen intacto ya que existe la creencia de que la extirpación de los órganos genitales externos disminuye el deseo sexual y, por tanto,

6 MORRIS, Desmond, The Naked Ape, Congi, 1967, p. 76. 
al impedir la posibilidad de goce de la mujer se reducen las posibilidades de fornicar. Así se garantiza la fidelidad al marido y éste tiene la garantía de que sus descendientes le pertenecen por completo, de que su sangre se reproduce en otra sangre. Este es el motivo de por qué a las niñas de siete y ocho años, antes de la llegada de su primer periodo menstrual o incluso a edades más tempranas, les realizan la escisión. La pureza es la máxima para ser aceptadas socialmente, para conservar la buena reputación, para poder acudir al matrimonio y que el hombre no las rechace (hasta las prostitutas se lo hacen), para no ser condenadas al ostracismo, para no ser tomadas por "sucias", para "controlar", como "forma de silenciar a las mujeres" (el trauma causado contribuye a desarrollar un comportamiento dócil que se considera muy positivo en estas sociedades). En el lenguaje popular se le llama "operación de limpieza o purificación". Encarnación Cabello va más allá a la hora de analizar el Código de familia que introdujo el Islam en el que el papel de la mujer, relegada al ámbito familiar, hace que el honor del mismo se circunscriba únicamente a la pureza sexual femenina :

"Aqui cabe preguntarse porqué sólo cuenta la pureza de la mujer en la salvaguarda del honor familiar y se cierran los ojos a la del hombre, si según el Corán el delito sexual lo es tanto si lo comete un sexo como si lo comete otro".?

"Sentía que me había librado de algo malo que tenía que ser extirpado, me sentí limpia y pura", "pensaba que era bueno para mi salud", "que se la hacían a todas las niñas por cuestiones de higiene, de purificación y para conservar la buena reputación"..., son algunas declaraciones hechas en total confidencialidad. Rose Oldfield afirma:

En Sudán existe un verdadero ejército de "dayas" que se gana la vida operando a las mujeres, tanto para extirparles el clitoris como para estrechar y ensanchar la apertura exterior, según la mujer esté casada, divorciada, casada en segundas nupcias, haya tenido un hijo o se esté recuperando del parto."

Conocida también como "ablación", la M.G.F. puede ser de cuatro tipos ( 4 grados) según sea la extracción parcial o total de los órganos genitales. El tipo de mutilación, la edad y la manera (individual o colectivamente, con un ritual sencillo o con grandes ceremonias acompañadas de música y danzas, en una fecha determinada o sin fecha fija, públicamente o de forma "secreta", de día o de noche...) varia según el grupo étnico, el país y el origen socioeconómico de la familia. Además de poner en peligro la vida de las niñas indudablemente la escisión supone un trauma sexual que incidirá plenamente en su deseo sexual y supone también un trauma psicológico que perjudica seriamente la salud de la mujer desde su más tierna infancia, "mutilándola" a los pocos años de vida. Nawal al-Sa'dawi aclara:

"Pero, sobre todo, la conmoción psicológica que sufria la niña en el transcurso de este proceso la iba a dejar marcada para el resto de su vida. Una de las consecuencias directas es la frigidez sexual, a la que también contribuyen otros factores sociales y

7 CABELLO SANZ, Encarnación, El concepto de lo femenino a traves del hombre y de la mujer árabes, UNED de Melilla. Málaga, 1983, p. 15.

8 OLFIELD, Rose, "Female genital mutilation, fertility control, women's roles, and patrilinenge in modern Sudan", American Ethnologist, Vol. II, N4, nov. 1975. 
psicológicos que influyen en la personalidad y la formación de las mujeres en las sociedades árabes".?

\author{
"Según el Islam, la obligación de \\ velarse (fesettür) simboliza el orden \\ social basado en la dualidad de sexos."
}

NILÜFER GÖLE.

\title{
2. EL "VELADO" DESPERTAR SEXUAL
}

La sexualidad de la mujer, su cuerpo y su feminidad se sienten como una amenaza para el orden y la paz social: "Hay que ocultar la belleza para no provocar desorden social". Nace y se educa a la mujer para ocultar y controlar su sexualidad y crece recibiendo de forma constante y continua toda una serie ilimitada de consejos y advertencias sobre lo que es dañino, perjudicial, vergonzoso, mal visto y prohibido por la religión. El Islam recoge este elemento cuyo origen más bien procedía de tradiciones anteriores, probablemente nómadas y zoroastrianas y lo formaliza como disposición. La obligación de velarse (tesettür) tiene como finalidad original el ocultar, el impedir que los hombres puedan mirar a las mujeres:

"Sustraer de las miradas de los hombres a las mujeres del Profela en particular, y a las mujeres creyentes en general, separarlas del resto del mundo por medio de una "cortina" -hiyab-"."

En este sentido Mernissi apunta que en un principio tendría la función (de la raíz del verbo hagaba) de "ocultar", de "sustraer a la mirada" separando los espacios íntimos entre hombres y mujeres y preservando sus respectivas intimidades. Pero además, habría otras dos dimensiones: establecer una "frontera", una especie de "barrera" entre los dos sexos y la que haria referencia al orden moral, ético, ya que el velo remitiria a "lo prohibido"." El "espacio" deslindado visual y espacialmente es un espacio prohibido, es haram. Pero se puede decir que existe también, relacionada con esa tercera dimensión de lo "prohibido", una "dimensión social", ya que la mujer llega a ser socialmente "invisible". Se la relega en esa original separación del mundo interior (la casa), el espacio íntimo-mahrem- y el mundo exterior (la vida pública), al ámbito de lo "intocable" -haram- ("harén") y se la recluye en el interior del espacio privado "invisible, oculto y prohibido" entre celosías (celos) para que sea inaccesible, llegando al actual "confinamiento secreto" del interior de la casa. Mi amiga tunecina Nora comenta:

"Lo que no practico de momento es el velo. Como mujer musulmana tengo que ocultar mi pelo y mi cuerpo. Por lo de mi cuerpo evito llevar ropa excitante y llevo ropa

9 AL-SA' DAWI, N., La cara desnuda, p. 60.

10 HELLER, Erdmute y MOSBAHI, Hassouna, Tras los velos del Islam, Herder. Barcelona, 1995, p. 162.

11 MARNISSI, Fátima, Le Harem politique, Albin Michael. Paris, 1987, pp. $119-120$. 
muy muy decente. Para mi, el velo me impide moverme como quiero, además no es un vestido muy práctico. Espero irme a peregrinar a la Meca y llevarlo pero una vez jubilada, "más vieja".'12

El Profeta, para conseguir que todo el territorio de la Peninsula Arábiga fuese un Estado islámico tuvo que hacer grandes concesiones a sus adversarios politicos en lo que respecta principalmente a los derechos de la mujer a la libertad. Tuvo que ceder ante la dura presión de una oposición patriarcal fuerte encabezada por su portavoz el misógino Omar (posterormente seria califa). Los preceptos, además de la obligación de velarse, se fueron haciendo por tanto, más rigurosos y severos:

" $Y$ di a las creyentes que bajen la vista con recato (en vez de quedarse mirando fijamente a alguien), que sean castas y no muestren más adorno que los que están a la vista, que cubran su escote con velo... Que no batan ellas con sus pies de modo que se descubran sus adornos ocultos. ${ }^{13}$

Desde entonces el Profeta continuó con tono más autoritario que no sólo implicaba la exclusión de la mujer de la sociedad sino que establecía un símbolo distintivo de "barrera" entre el islam y las demás religiones. Shaima escribe:

"Si deseas conocer lo que la religión musulmana ordena a la mujer en torno de dichas actitudes, bueno, francamente, no conozco mucho pero te digo lo que sé a ciencia cierta. Generalmente la mujer no debe fijar la mirada en los demás y sobre todo en los hombres extranjeros de ella, es decir, los que no tienen ningün parentesco con ella y ni siquiera eso debe ser en exceso (padre, hermano, marido, hijo y tio). En general, la mujer musulmana se caracteriza por la timidez en todos sus actos. Su voz no debe ser muy alta o alzarla de manera llamativa". ${ }^{14}$

Boutheyna se expresa de la siguiente forma:

"Al principio tengo que decirte que la tunecina mujer musulmana no es como otra musulmana en otro pais arábigo. Es decir, que la tunecina mujer musulmana vive hoy día una gran emancipación. Dicho de otra manera, que esta mujer - como yo -, no repeta perfectamente la religión. Seguramente tengo mis motivos. Nuestro pais y su politica impide la mujer que estudia o trabaja de poner la ropa que necesita nuestra religión (sólo la cara aparece). Pero mi familia quiere siempre que yo repete la religión. Cuando era niña, mi familia me habló siempre del "islam" y de sus reglas. Hasta ahora leo el "corán" y hago la oración.

Sin duda, hay algunas mujeres que no están convencidas del "islam", porque no sienten libres con todas sus reglas. Yo, por ejemplo, creo a nuestra religión y estoy convencida, pero a veces algunas reglas me molestan, me parece duro de practicarlas $y$

12 Carta de NORA DEBBACHE de 25 de abril de 1999 desde Argel (Argelia).

13 El CORAN $(24,31)$.

14 Carta de SHAIMA MOHAMED de 16 de abril de 1999 desde El Cairo (Egipto). Trabaja en el Consejo Superior de Juventud y Deportes de su pais. 
respetarlas. Por ejemplo el problema del sexo. La mujer musulmana no tiene que hacerlo antes de casarse.

Tú sabes que tengo un novio hace cinco años y estamos enamorados, pero no hacemos nunca el amor (o el sexo). ¿Crees que esto es fácil para nosotros? En este punto yo respeto no sólo mi religión, pero también mi familia musulmana. Yo vivo entonces con limites, el islam ordena mi vida y ni comportamiento, asi yo descuido los diferentes anhelos que pueden estar contra la religión. La mujer musulmana da una gran importancia al futuro con su marido y quiere formar una familia que será también musulmana.

Oñez, querria ser una verdadera mujer musulmana, pero esto será una gran responsabilidad". 's

La idea de velarse, de ocultar su cuerpo y su feminidad, hay que situarla en una educación. "Una mujer musulmana que ha optado por el velo ha optado por la virtud".

"Como se puede apreciar, el velo de la mujer ha sido investido de la función de defender el orden de la comunidad y establecer las fronteras entre los sexos". ${ }^{16}$

El acto sexual sólo y exclusivamente se puede practicar dentro del matrimonio y por ello a los jovenes, como explica Boutheyna, sólo les queda esperar. Se prohibe cualquier actividad sexual fuera de este marco legal. Existe una segregación de los sexos y ambos viven la sexualidad entendida como pecado. Estas situaciones en estas sociedades patriarcales van creando un alto nivel de frustraciones y represiones sexuales.

"Muchas niñas en nuestra sociedad se exponen durante su infancia a diferentes tipos de agresiones sexuales, desde caricias y juegos amorosos con las manos hasta relaciones sexuales completas. Cualquier niña puede perder la virginidad sin ni siquiera darse cuenta. Al final terminará olvidando lo que le sucedió o lo recordará simplemente como una pesadilla que la atormentará y minará su salud mental durante toda la vida"."

El velo del silencio se tiende por el alma de la niña marcada para siempre por la agresión. Guarda su secreto por miedo, por vergüenza, porque ella es quien pierde. Pierde su virginidad, su himen, su honor... Lo pierde todo. Si lo denunciase o se descubriese in fragan$t i$, la familia lo ocultaría y se negaría a denunciarlo para salvar el honor y la reputación (puede ser un miembro de la misma). En caso de ser un hombre ajeno a la familia, el castigo más severo que le pueden imponer, si es que existe una denuncia y se le juzga, es que se case con ella. Podría tratarse de casos o sucesos aislados, irrelevantes, pero son desgraciadamente muy frecuentes y cotidianos. Es increible el nivel de violencia sexual que soportan las mujeres no sólo en algunos paises islámicos sino en general en el denominado "Tercer

15 Carta de BOUTHEYNA FARHAT de 8 de abril de 1999 desde Zaghouan (Túnez). Trabaja en la Organización Tunecina de Albergues Juveniles de su pais.

16 GÖLE, Nilüfer, Musulmanas y modernas. Velo y civilización en Turquia, Talasa. Madrid, 1991, p.l14.

17 AL-SA'DAWI N., La cara..., pp. 43 y 44. 
Mundo". El Instituto Panos de Londres llega a conclusiones tan terribles como que las agresiones sexuales provocan más muertes entre las mujeres de 15 a 44 años que el cáncer, la malaria e, incluso, la guerra.

"El matrimonio es la mitad de la fe". (DICHO POPULAR ÁRABE).

"La llave del paraiso está a los pies de las madres". ( EL CORÁN).

\section{MATRIMONIO "VIRGEN"Y MATERNIDAD}

Desde niña se la educa a la mujer para el matrimonio. Puede llegar a ser el motivo de su existencia. Es la institución que, por antonomasia, le da el estatuto de mujer en la sociedad islámica. El casarse, ser buena esposa, servir a su marido (tiene la "obligación de estar siempre a disposición del marido"), ser madre, concebir y cuidar hijos, preferiblemente varones, es la finalidad de su vida. Shaima me escribe:

"En cuanto a sus inquietudes o preocupaciones, los padres desarrollan en la chica el instinto de ser esposa, madre o ama de casa y asi crece con la inquietud de casarse $y$ de tener una familia a la que cuidar y eso nos conduce al punto de su feminidad que sólo practica después del matrimonio. Aqui, en la sociedad oriental, la muchacha debe ser virgen hasta el dia de su boda (mi cara se convierte roja ahora)". ${ }^{18}$

Y el comienzo del matrimonio es la "dakhla"(la entrada del marido en el dormitorio y la desfloración), la demostración de la "honrosa virginidad"...

"Parece natural que, como las agresiones sexuales a chicas y niñas son tan frecuentes, las estratagemas que se emplean para reparar la pérdida de la virginidad sean también muy usuales. Los métodos utilizados van desde una operación quirúrgica para reemplazar el himen hasta simular pérdida de sangre durante la desfloración".19

Por otra parte, no se tiene en cuenta en el desvirgamiento la realidad plural del himen que puede sufrir numerosas anomalias en la fase del desarrollo embrionario y que varía de una mujer a otra pudiendo en aproximadamente un $16,16 \%$ de los casos, debido a su fragilidad, malograrse. Mi amiga Nora me escribe:

"Lo de ligar novios está prohibido en el Islam. El único hombre que toca a la mujer debe ser su marido y no la toca hasta que sea su mujer ante Dios y sus seres. La mujer musulmana tiene que guardar su virginidad, que es simbolo del honor, hasta que se case. Si no se casa, tiene que morir virgen, inmaculada (por su sangre de virginidad) y se le llama "peregrina"; o sea, "la inmaculada". Porque lo peor de los pecados es el adulterio que engendra hijos bastardos y desdichados" ${ }^{20}$

18 Carta de SHAIMA MOHAMED (lbid.).

19 AL - SA'DAWI, N., La cara..., p. 45.

20 Carta de NORA DEBBACHE (Ibid.). 
Tanto para el hombre como para la mujer, todas las escuelas y sectas musulmanas reconocen tradicionalmente en la figura de su tutor, la persona que tiene el derecho de prometerle en matrimonio sin su consentimiento. El 9 de abril del presente año, saltaba a los periódicos la noticia de que Besra Kiran, una joven turca de 23 años, se quitó la vida porque pensó que la muerte era la única salida que tenía para impedir casarse con su primo, un hombre al que no amaba. La boda, al igual que el de muchas otras jovenes como ella, fue concertada por su padre; impuesta, como sucede en muchos países islámicos donde la estructura familiar tradicional sigue siendo muy rigida, a la decisión del Consejo de Familia. Luchar contra estos acuerdos, contra estos matrimonios de conveniencia, resulta casi imposible y es que sus mandatos están, como señala una experta en estos temas, "por encima de las leyes". El silencio y las sombras "velan" estos dramas humanos que se repiten a menudo y raras veces son recogidos por los medios de comunicación, son conocidos en el mundo. El peso de la tradición es aplastante y la población ofrece una resistencia, a veces "ciega", a cambiar el rumbo de las cosas y poner fin a estas dramáticas y terribles situaciones que pueden acabar y de hecho acaban, como en este caso, en tragedia y muerte. Hay jóvenes que se atreven a huir y se lanzan a la aventura de vivir sin importarles cómo ni dónde, desarraigadas de todo buscando vivir una nueva vida, la mayor parte de las veces en la más absoluta indigencia y miseria: Yo tuve que huir porque lo normal era casarse. No podia decir "prefiero no hacerlo". La única forma de evitarlo era desaparecer"... Existen otras jóvenes que no optan por el suicidio pero al enfrentarse a la autoridad masculina, en estas sociedades donde ante las decisiones de los hombres las mujeres no tienen más opción que acatarlas, "la osadía" y "el atrevimiento" puede costarles algo "peor que la muerte" en palabras de la doctora Luna Ahmned. Es el caso de las mujeres bengalies que por rechazar a un pretendiente o disgustar a su marido sufren actos tan viles como el que les arrojen a la cara ácido sulfúrico. Se ven condenadas al suplicio de pasar el resto de sus dias con el rostro completamente desfigurado. Al ser un ácido tan poderoso, ya que se filtra rápidamente en la piel, puede afectar también a los huesos y a veces las quemaduras son tan graves que pueden dejar ciegas a algunas jóvenes.

Nawal al-Sa dawi dedica su libro "La cara desnuda de la mujer árabe" de esta forma:

"Dedicado a Zaynab Shukri, esa gran mujer que vivió y murió sin darme su apellido: mi madre".."

La mujer esposa obediente y dócil a los deseos de su marido debe procrear (la sexualidad se ejerce con la finalidad de la reproducción y de ahi el miedo a la esteriliad) y ni siquiera puede dar su apellido a sus hijos como acabamos de ver. La mujer es mujer en tanto que esposa y madre. Según los sociológos magrebies se puede llegar a afirmar que el matrimonio es el que da la existencia a la mujer.

"Tanto es asi que la mujer no sólo se define por su familia o por su marido, pero nunca por ella misma, por sus méritos o experiencia. Una vez casada, es el marido quien da una situación a la mujer, $y$ ante cualquier eventualidad en la nueva vida de

21 AL-SA'DAWI, N. La cara..., p. 13 
casada, los padres son una defensa frente al marido y suegros, y el no tenerlos podria justificar el peor de los tratamientos que se puedan dar a la mujer".22

Pese a que el matrimonio, "nikah", proporciona a la mujer su "razón de ser", el Código de familia que introdujo el Islam y que fundamenta el actual, la define por su estatuto como menor. Éste, sólo llega a superarlo en parte en la edad adulta y en el ámbito de su papel en la familia fundada. Es decir, cuando en su madurez "domine" a su vez a otras mujeres y por tanto las relege al citado estatuto y asuma los roles dentro de la familia que forme, como esposa: sumisa, obediente y dócil a su marido y madre que cuide no sólo de la casa sino de los niños y su educación. El asumir de nuevo los esquemas, valores y estatutos marcados hacen que se continue y se prosiga esta cadena de discriminaciones y desigualdades. Sin embargo, pese a esta situación "sostenida"...

Muchas mujeres son sensibles a esta nueva lectura de la religión, donde el deber de obedecer que conocen tan bien, ya no es incompatible con una libertad que no terminan de imaginar. ${ }^{23}$

Se trata de jóvenes o ya no tanto, que como las autoras que se citan en el trabajo, pese a haber sido educadas y haber vivido inmersas en esas "reglas", en esos "límites", en esos "umbrales"... han sabido y han podido, no sólo soñar, sino traspasarlos y "volar"; no sólo liberarse, sino alzar su voz y desvelar su mirada, abriéndonos los ojos a todo y a todos...

"La libertad de recorrer las calles a su antojo era el sueño de cada mujer. En ocasiones señaladas, tía Habiba solia relatar su cuento más celebrado; trataba de "la mujer con alas", una mujer que podia irse volando del patio cuando le venia en gana".24

\footnotetext{
"Las conquistas de igualdad y progreso que disfrutamos no se consolidarán mientras no sean compartidas también por las mujeres que, como las argelinas, sufren la violencia y toda suerte de penalidades, por su condición de mujeres". MARÍA PATROCINIO LAS HERAS PINILLA.
}

\section{LA MUJER “CAMALEÓN": UNA VOZ LIBRE DESDE ARGELIA}

Transcribo literalmente una voz que desde Argelia valientemente describe la terrible realidad actual en que vive su país, en que vive la mujer musulmana. Su bipolar situación personal es común a otras muchas mujeres. Es la voz alada, que subsiste y sobrevive, de mi

22 CABELLO SANZ, E. El concepto..., pp. 25 y 26

23 BESSIS, Sophie y BELHASSEN, Souhayr, Mujeres del Magreb. Lo que està en juego, "Horas y Horas la editorial". Madrid, 1994, p.171.

24 MERNISSI, Fátima, Sueños en el umbral. Memorias de una niña en el harén, Muchnik Editores. Barcelona, 1997, pp. $152-153$. 
amiga Leyla que desde Tizi-Ouzu (Argelia) nos llega repleta de las voces ya silenciadas de mujeres asesinadas.

No puedo por menos que cerrar mis labios para que a continuación escuchemos en cuerpo y alma este clamor, este grito de coraje de esta mujer que resume todo el compendio de sangre, discriminación, desigualdad injusticia, tragedia, dolor y sufrimiento femenino que encierra el integrismo islámico. Desde su tierra, sin renunciar a nada, en medio de su pueblo, intenta buscar justicia y paz; desde la fortaleza de su debilidad, busca esperanzada conquistar entre, con y para los suyos, la cima de la libertad:

"El tema de la mujer musulmana es muy extenso pues hay tantos casos de mujeres musulmanas como mujeres según el pais, la ciudad, el pueblo o la familia en la que se encuentren. Pero nuestro denominador comin es que las mujeres han sido traicionadas por los hombres que administran nuestro pais y que nos hacen sufrir la religión tal como ellos la interpretan. Argelia es el mejor ejemplo.

Antes de 1988, nosotras las mujeres argelinas eramos alegres, libres. Era estudiante en Argel. Fue un periodo muy bueno, habia paz en Argelia. Se vestia como se queria, se hacia deporte, se iba a restaurantes, a discotecas... se hacia autostop... Para nosotras estas actividades normales se volvieron actos de rebelión por los que podian condenarnos a muerte. ¿Cuántas mujeres han sido asesinadas por haber rechazado llevar el velo o bien porque se han encontrado con un hombre que no era su marido? Desde la legalización de los partidos politicos nuestra vida se ha vuelto infernal, la pesadilla habia comenzado. El método de los islamistas está basado en el miedo y el terrorismo. Si una mujer no se doblega a sus Leyes, será simplemente asesinada. Los islamistas tienen una idea muy clara de la mujer: La primera es que la mujer es inferior al hombre en todos los ámbitos. Su lugar está en el hogar por lo que no tiene necesidad de ir al colegio. ¿De qué le va a servir la enseñanza si solamente se tiene que encargar de tener hijos y cuidarlos? La mujer debe observar unos modales estrictos. Debe llevar una ropa que evite al máximo mostrar su cuerpo o mejor dicho, la formas del cuerpo pues, según éstos, puede excitar a los hombres. La mujer debe vivir para hacer todos los favores que desee el hombre y si desobedece debe aceptar un castigo. Para ellos, una mujer está en este mundo para satisfacer al hombre. Es su misión divina. No puede escuchar música, cantar o bailar pues estas actividades pueden darles ideas, pueden incitar a las mujeres a resbalarse. En lineas generales, la única cosa que le incumbe es hacer las tareas domésticas, dar gusto a los varones y tener hijos. En 1984 el gobierno adoptó un código de familia que degrada a la mujer. Queda como menor de por vida. He aqui algunos ejemplos. Una mujer sólo puede casarse si está presente un tutor legal. El tutor puede impedir el matrimonio. Un hombre puede casarse por procuración. Es decir, puede dar un impreso por ejemplo a un amigo suyo, en el que suscribe que no puede firmar él mismo su matrimonio y delega este acto a su amigo. En caso de divorcio, si la vivienda es única, la mujer no tiene derecho a la misma, aunque ésta tenga la custodia de los niños. Esto sucede aún cuando en el caso de Argelia se sabe que el problema de la vivienda es un problema esencial. No es extraño ver a las mujeres con sus hijos en la calle sin un techo donde meterse, mientras que de forma normal, el marido se vuelve a casar. Trae otra mujer a la casa y vuelve a empe- 
zar. La justicia está con él. Si la mujer quiere trabajar; debe negociarlo con su marido, pues si trabaja sin su consentimiento, éste declara que ella ha efectuado un abandono del hogar y el divorcio se pronuncia en su contra. En lo que concierne a la poligamia, el hombre puede casarse hasta 4 veces. En caso de divorcio, si la custodia viene a ser de la madre, ésta no tiene el derecho de tutela. No tiene el derecho de poder firmar los papeles oficiales del niño. Por ejemplo, si quiero salir con mis hijos fuera del territorio nacional debo conseguir la autorización paterna para ellos de salida del territorio. Esto quiere decir que sin estos famosos papeles no me dejarian salir del pais. De esta forma, cuántos hombres para vengarse de ellas, rechazan hacer estos papeles y los proyectos de las madres caen por tierra. Con estas Leyes por una parte y los terroristas por otra con sus ideas integristas, nosotras, las mujeres argelinas, sufrimos.

Yo misma, soy una mujer tolerante, defiendo la laicidad. Provengo de un medio muy liberal, pero debo someterme a las reglas de la sociedad. ;Un verdadero camaleón! Aqui en Kalylie, se puede vestir como se quiera. Vivo al lado del mar y voy a bañarme en bañador; pero es suficiente cambiar de ciudad, por ejemplo si voy a ciertos barrios calientes de Argel (donde hay muchos islamistas) y procuraré vestirme de fasm. No puedo destacarme en estas ciudades, tengo la impresión que pertenecer al sexo femenino es una tara. No se puede vivir la feminidad. Lo que me hace exclamar: ¡Incluso si no se lleva el velo! Hav que llevarlo en la cabeza y se debe observar esta norma todo el tiempo porque se tiene miedo de la violencia de ciertas gentes que espian a las mujeres. Si pudieran serian como los talibanes. Y además de todo esto, la pobre chica está sometida al test de la virginidad en su boda. Si no es virgen, puede ser asesinada por su padre. Las muchachas que son madres son igualmente asesinadas. Además de este problema, como el aborto está estrictamente prohibido, las madres adolescentes son hospitalizadas en una clínica lo más lejos de la ciudad, traen al mundo a sus hijos, los abandonan y después se vuelven a reunir con los de su casa.

Pero felizmente hay en Argelia mujeres y hombres que quieren avanzar y que rechazan este estado de cosas. Todos los verdaderos demócratas demandan la abolición del código de familia, además de la igualdad entre la mujer y el hombre, sobretodo ante la Ley. Para mi, hoy por hoy, es como yo veo a la mujer musulmana. En primer lugar, los hombres musulmanes deben saber que una mujer tiene un cerebro. Se debe reflexionar más en esta cuestión. No se debe obligarla a hacer esto o a no hacer aquello. Ella debe hacerse cargo de su vida. Es necesario que su feminidad deje de ser una tara. Debe participar en las actividades que le gustan como los deportes, la musica... $Y$ sobretodo la justicia debe protegerla contra los abusos de los hombres. Pienso que la enseñanza y la educación deben ser obligatorias para las chicas para que éstas puedan alcanzar su plenitud y vivir plenamente su propia vida. Tengo una niña de 4 años y un niño de 6 meses. Quiero darles las mismas oportunidades en la vida. No quiero que se imponga lo que sea a mi hija o que le prohiban hacer una actividad porque sea una niña. Como ves, Oñez. el problema de la religión es muy pasional entre nosotros. Ha dejado miles y miles de muertos. Pero se continua la lucha por la democracia. ${ }^{25}$

25 Carta de LEYLA AZZAM de 5 de mayo de 1999 desde Tizi-Ouzu (Argelia). 
"Las fronteras entre lo privado y lo público mahrem/namahre, el interior y el exterior, experimentan un cambio a partir de las reformas y comienzan a modificar la vida de las mujeres".

NILÜFER GÖLE.

\section{EL FUTURO: ¿UN HORIZONTE SIN "FRONTERAS”}

Después de todo lo dicho por Leyla creo que queda muy poco que decir. No obstante reflexionemos sobre sus palabras e intentemos esa búsqueda, personal y única...

"Mi padre decía que con los cristianos, al igual que con las mujeres, los problemas empiezan cuando no se respeta la frontera sagrada o "hudud". Yo naci en pleno caos, porque ni los cristianos ni las mujeres respetaban las fronteras (...).

(...) Existe armonia cuando cada grupo respeta los limites de los demás; la transgresión sólo causa pena y desdicha. Pero las mujeres soñaban continuamente. Su obsesión era el mundo del otro lado del umbral". ${ }^{26}$

Las "fronteras", "los umbrales", "las barreras"... bloquean, coartan, delimitan, esclavizan... Las separaciones, disgregaciones, distanciamientos conllevan a incomprensiones, marginaciones, prejuicios, miedos, rechazos, hostilidades...

"Mina no me respondió contestando a mis preguntas sino diciéndome que la separación hacia desgraciados tanto a los hombres como a las mujeres. La separación crea un inmenso vacio de comprensión.

Los hombres no comprenden a las mujeres -dijo-, y las mujeres no comprenden a los hombres, y todo empieza cuando se separa a las niñas de los niños en los baños. Entonces, una frontera cósmica divide el planeta en dos. La frontera señala la linea de poder, porque dondequiera que haya una fiontera, hay dos clases de criaturas que caminan por la tierra de Alá: de un lado, los poderosos, y, de otro, los impotentes.

Pregunté a Mina cómo sabría yo en qué lado respuesta fue rápida, breve y clarisima: Si no puedes salir, estás en el lado de los impotentes". ${ }^{27}$

Nora explica:

"La mujer musulmana actualmente vive un conflicto peliagudo. Hablando de mi, yo me las arreglo como puedo. Aplico al máximo las reglas del Islam, y dejo lo que no puedo de momento. Lo que aplico ahora es la oración, cinco veces al día, la limosna cuando me la piden los mendigos y aún sin pedirmela. Cuando veo a una familia que necesita ayuda iy son tantas! la ayudo; sin esperar nada a cambio. Evito mentir al máximo, soy sincera en todo lo que hago, sobre todo en mis sentimientos con los demás. Quiero a todo lo que creó Dios Todopoderoso y lo respeto también. (...) Cada una interpreta el Islam y lo adapta a su vida". ${ }^{28}$

26 MERNISSI, F., Sueños..., pp. 9 y 10.

27 Ibid., p. 292,

28 Carta de NORA DEBBACHE (Ibid.). 
Shaima hace la siguiente reflexión:

"Pienso que la mujer musulmana no es difierente a cualquier otra mujer en el mundo y que sus actitudes (voz, mirada, anhelos, etc...) cambian segun las tradiciones: $y$ las costumbres de su pais (...) hay que decir que la aplicación de dichos órdenes-de la religión- no es igual en todas las mujeres, pues, como sucede en cualquier sociedad, existen las practicantes y religiosas, las moderadas y las putas ¿no? ".

Decía Arthur Koestler que "todos tenemos la suficiente religión como para odiarnos, pero no la necesaria para amarnos unos a otros"...

Durante más de veinte años el pueblo saharaui, "los hijos de las nubes", sobreviven sedentarios en la "hamada" (existe una maldición árabe que dice: "Ojalá que Alá te condene a vivir en la hamada") una llanura de piedras, un "pantano de arena", que nadie antes se habia atrevido a habitar. En este territorio tan inhóspito, en los organizados campamentos de Tindouf, la libertad de movimientos de las mujeres saharauis es practicamente absoluta y pueden llegar a ser alcaldesas.

“(...) aqui (campamentos saharauis), se nombra a la gente por su competencia. Es el único criterio que se tiene en cuenta...(...) lo más dificil es confiar a cada uno la tarea que le convenga más y que cada hombre y cada mujer estén a gusto en su trabajo, al nivel en que cada uno se encuentre". ${ }^{30}$

Sin embargo también es necesario hacerse la siguiente reflexión:

"La evolución de las mentalidades concerniendo a la mujer y su lugar en la sociedad se ha hecho sólo cuando las necesidades económicas y sociales han obligado a ello: un caso extremo y que sirve como ejemplo son los periodos de guerra. Asi tenemos el conocido caso de la mujer argelina en la lucha por la independencia nacional, para una vez conseguida, ser reclamada al interior de los hogares con más fuerza moral que antes. En el presente, atraviesan el flujo de la participación en la guerra, la mujer palestina y la saharaui. Lo que ocurra con ellas una vez alcanzadas las metas, se verá". ${ }^{31}$

Alguien dijo una vez que "Si queremos que las cosas cambien alguna vez, tendrá que ser a fuerza de hablar de ello. De otro modo, siempre seguirá igual'... En la actualidad en Arabia Saudí, país musulmán emblemático (el islam nació en Arabia y debido a su expasión los árabes representan la sexta parte de los musulmanes, tienen el mismo origen que el Profeta y la lengua árabe es la lengua litúrgica del mundo islámico) las mujeres deben salir siempre con el velo y acompañadas, no pueden acceder a determinados estudios, no pueden conducir y ni siquiera poseen un documento de identificación, de acreditación, un carnet de identidad...

29 Carta de SHAIMA MOHAMED (Ibid.).

30 PERREGAUX, C., Gulili, mujeres del desierto saharaui. Ed. Txalaparta.

31 CABELLO SANZ, E., El concepro..., p. 16. 
"La cuestión de la mujer está en el corazón mismo del debate: en un país musulmán, el papel de la mujer en la sociedad define los retos mismos de la occidentalización y, más allá de las condiciones de vida de las mujeres, cuestiona de manera general la cultura y la civilización". ${ }^{2}$

Empiezan a surgir voces de hombres que se suman a las de muchas mujeres que desean, que quieren sinceramente avanzar, y que rechazan este estado de cosas. Todos los verdaderamente "demócratas" demandan la abolición del Código de familia y reclaman la igualdad entre el hombre y la mujer sobretodo ante la Ley. Hombres, como el marroquí Tahar Ben Jelloun, premio Goncourt de Literatura en 1987, que el 31 de diciembre de 1994 declaraba en los medios de comunicación:

"Mientras la condición de la familia y, en particular, la de la mujer no hayan evolucionado, mientras sea injusta y retrógrada, los totalitarismos se podrán imponer en nuestras sociedades, bien tengan cubierta ideológica, bien religiosa".

Los problemas no se reducen a si las mujeres tienen que llevar velo o no, hay mucho más trasfondo en la situación que viven: político, social, económico... En Bangladesh cuando faltan alimentos, las mujeres son las primeras que no comen...

"Son muchas las caras de la pobreza: la mayoria de ellas tienen el rostro de mujer. Según el "Estudio Mundial sobre el papel de la mujer en el desarrollo, 1994" de Naciones Unidas, la tradición discriminatoria es una de las razones por las que la mujer tiene que soportar la mayor carga de la pobreza, especialmente en las zonas rurales, donde el acceso de la mujer a la salud, la educación y a los recursos productivos está gravemente limitado.(...) Más de 550 millones de mujeres del campo, más del $50 \%$ de la población rural mundial, viven por debajo del umbral de la pobreza. La "feminización" de la pobreza es un fenómeno que no ha hecho más que crecer en los últimos años: desde 1975, el numero de mujeres pobres del planeta ha crecido en un $50 \%$, frente al $30 \%$ en el caso de los hombres. ${ }^{3 .}$

La ausencia de democracia ayuda a mantener a la mujer en una posición de inferioridad y a aprobar un flagrante analfabetismo que la discrimina. Por ejemplo el analfabetismo entre las mujeres magrebíes es muy elevado: $66 \%$ en Marruecos, $45 \%$ en Argelia, 55\% en Túnéz. El pasado 8 de septiembre "Día Mundial de la Alfabetización", el secretario de Naciones Unidas manifestaba que existen en el mundo 880 millones de analfabetos de los cuales dos terceras partes son mujeres. Semsettin Sami comenta que "el nivel de desarrollo de una sociedad es siempre proporcional a la condición de las mujeres en esa sociedad" y apoya y defiende la idea de "que educando a las mujeres se educaráa a toda la humanidad". Un proverbio de Malí dice que "ser mujer no es ninguna tragedia, pero sí lo es el fracasar como mujer".

32 GÖLE, N., Musulmanas ..., p. 113.

33 Según Informe del PNUD. 
A lo largo de quince siglos de islamismo, nos cuenta Fátima Mernissi, desde el año 1 de la Hégira (622 d. C.) hasta nuestros dias, se ha tendido el "tupido velo" del olvido sobre mujeres que han sido protagonistas de la historia islámica, que acuñaron moneda y que llegaron a ejercer el máximo símbolo del poder en las sociedades mahometanas: que la plegaria del viernes en la mezquita se dijera en su nombre. Ella misma representa el mejor avance de un futuro prometedor y esperanzador. Desde pequeña supo que algún día, cuando fuese mayor, haría grandes cosas". ${ }^{34}$

Oh, sí, les hablaria de los imposibles, de un mundo árabe nuevo en que los hombres y mujeres pudieran abrazarse y bailaran sin miedo y sin barreras que los separasen.

Oh, si, encantaría a mi público y, con palabras mágicas y gestos estudiados, como Asmaham y Chama antes que yo, recrearia un planeta sereno en que las casas no tuvieran puertas y las ventanas se abriesen de par en par a las calles seguras.

Les ayudaría a caminar en un mundo en que la diferencia no precisara velos y donde los cuerpos de las mujeres se movieran con naturalidad $y$ sus deseos no crearan angustia.

Crearía para y con el público largos poemas sobre la ausencia de miedo. La confianza sería el juego nuevo que podriamos explorar y confesaría humildemente que yo tampoco sabia nada de él.
Ganaría dinero suficiente en mi teatro para servir té y galletas, de forma que los espectadores pasaran largas horas relajados asimilando la nueva jdea de un planeta en que la gente caminara sin miedo a nada.

Sólo caminar, un pie delante del otro, con los ojos fijos en un horizonte nuevo, casi inconcebible $y$ sin amenazas.

Convenceria a todos de que la dicha puede florecer por doquier hasta en las callejas oscuras de las Medinas agredidas.

Asmahan, yo la reivindicaria. Ella podia existir y no sólo como victima trágica. Podría haber Asmahans que no tuvieran que morir a los treinta y dos años en oscuros complots extranjeros y absurdos accidentes de coche.

Las consabidas preguntas surgen y afloran ante la diversidad de circunstancias y la realidad específica de cada país. ¿Se dan gestos? ¿Se dan pequeños pasos? ¿Qué se hace?. Algunas mujeres han sido las primeras en hacer su voz "pública" y elevarla en la política como Jeanne Martin Cissé, Elizabeth Bagaya, Benazir Bhuto o Mariama Hima.

El 23 de octubre de 1998, se entregaron los premios Príncipe de Asturias de Cooperación Internacional a siete mujeres por su lucha a favor de la mujer y la defensa de los derechos humanos. Dos de ellas son de países islámicos: Fatiha Boudiaf, que preside una fundación que ayuda a mujeres argelinas, sobre todo a las viudas de victimas de la violencia y la afgana Fatana Ishaq Gailani. Además de otra mujer de Nigeria, país con población musulmana en el norte, Olayinka Koso-Thomas que se ha distinguido por la lucha a favor de la abolición de la mutilación genital femenina. Son una minoría privilegiada, pero su esfuerzo, su lucha, su vida, hacen que día a día logren que la dignidad, el respeto, el derecho y la igualdad de muchas mujeres deje de ser un sueño y se haga realidad.jOjalá (palabra árabe que significa "Dios lo quiera") esas voces se multiplen y se transformen en compromiso y entrega! 
"(...) la mujer musulmana tiene las mismas aspiraciones que cualquier mujer. Personalmente practico deporte, viajo, condizco un coche, trabajo y sé que Dios no me impide ser un miembro activo en la sociedad, siendo piadosa y puidica (...) Si quieres venir aqui para ver cómo me comporto y cómo se comporta la mujer musulmana, te invito a pasar unos días con mi familia, porque hay tantas cosas que tú puedes anotar y yo no; pues, las veo como normales... ¿Qué más decirte? Pues te ruego que vengas tú misma y veas cómo se vive aqui" " ${ }^{35}$

Convivir y compartir su vida... abriendo nuestras propias "fronteras", nuestros propios "límites"... intercambiando, enriqueciéndonos, interrelacionándonos interculturalmente con todo el respeto y con amistad. Creándo juntos historia en paz y solidaridad.... sin intransigencias, sin imposiciones,... en libertad. Para terminar, me uno a la voz del profesor Miguel Cruz Hernández:

"Pero esto sólo puede conseguirse con dos medios: el conocimiento y el amor, y las informaciones y "desinformaciones" que sobre ellos y sobre nosotros se nos lanzan a diario no contribuyen a ello. Esperemos que alguna vez no sea asi, "Inchá Allah".

Por último quiero expresarles mi gratitud por su atención e interés y como no dar las gracias también a todas mis amigas magrebies, a las que me han escrito y me han enviado documentación (pese al miedo y las represalias) y a las que han guardado silencio. Todas, han hecho posible este sencillo relato, llenándolo de sentido y de autenticidad. Todo mi profundo cariño, respeto y admiración por estas jóvenes mujeres héroes que, sin perder su identidad y su cultura, su amor por su pueblo, "sangran, luchan, perviven... para la libertad". Ellas, y otras muchas como ellas, hacen posible en su pequeño gran quehacer cotidiano que el futuro de la mujer en sus respectivos paises sea más abierto, más tolerante y solidario, porque su voz es sincera y su mirada limpia. ¿Nos unimos a ellas?... 